\title{
Immunohistochemical characteristics of porcine intrahepatic nerves under physiological conditions and after bisphenol $A$ administration
}

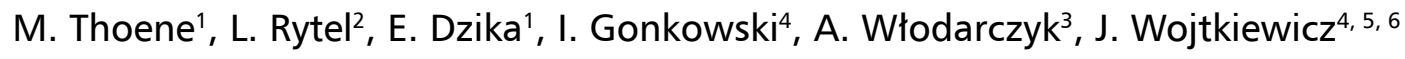 \\ ${ }^{1}$ Department of Medical Biology, Faculty of Health Sciences, University of Warmia and Mazury, Olsztyn, Poland \\ ${ }^{2}$ Department of Internal Medicine and Clinic, Faculty of Veterinary Medicine, University of Warmia and Mazury, \\ Olsztyn, Poland \\ ${ }^{3}$ Department of Public Health, Epidemiology and Microbiology, Faculty of Medical Sciences, of Warmia and Mazury, \\ Olsztyn, Poland \\ ${ }^{4}$ Department of Pathophysiology, Faculty of Medical Sciences, University of Warmia and Mazury, Olsztyn, Poland \\ ${ }^{5}$ Laboratory of Regenerative Medicine. University of Warmia and Mazury, Olsztyn, Poland \\ ${ }^{6}$ Foundation for Nerve Cell Regeneration, Olsztyn, Poland
}

[Received: 19 September 2017; Accepted: 5 February 2018]

Background: The neurochemistry of hepatic nerve fibres was investigated in large animal models after dietary exposure to the endocrine disrupting compound known as bisphenol $A$ (BPA).

Materials and methods: Antibodies against neuronal peptides were used to study changes in hepatic nerve fibres after exposure to BPA at varying concentrations using standard immunofluorescence techniques. The neuropeptides investigated were substance $P(S P)$, galanin (GAL), pituitary adenylate cyclase activating polypeptide (PACAP), calcitonin gene regulated peptide (CGRP) and cocaine and amphetamine regulated transcript (CART). Immunoreactive nerve fibres were counted in multiple sections of the liver and among multiple animals at varying exposure levels. The data was pooled and presented as mean \pm standard error of the mean.

Results: It was found that all of the nerve fibres investigated showed upregulation of these neural markers after BPA exposure, even at exposure levels currently considered to be safe. These results show very dramatic increases in nerve fibres containing the above-mentioned neuropeptides and the altered neurochemical levels may be causing a range of pathophysiological states if the trend of over-expression is extrapolated to developing humans.

Conclusions: This may have serious implications for children and young adults who are exposed to this very common plastic polymer, if the same trends are occurring in humans. (Folia Morphol 2018; 77, 4: 620-628)

Key words: bisphenol A, BPA, nerve fibres, endocrine disrupting compounds, EDC, xenoestrogen, child development

\section{INTRODUCTION}

In our modern world, artificial polymers are found all around. Unfortunately, at least one of those polymers may be causing serious deleterious health effects, even at extremely low doses. Bisphenol A (BPA) has been used for several decades as a key monomer in the production of polycarbonates, and is also known as BPA or simply bisphenol. BPA is mainly

Address for correspondence: Mgr M. Thoene, Department of Medical Biology, Faculty of Health Sciences, University of Warmia and Mazury in Olsztyn, ul. Żołnierska 14C, 10-561 Olsztyn, Poland, tel: +89 52461 16, e-mail: michael.thoene@uwm.edu.pl 
used for the manufacture of plastic linings found in metal food and soft drink containers, since the plastic shields the contents from absorbing a metallic taste. However, BPA has also been used in the fabrication of plastic bottles, dental prosthetics, thermal paper, food storage containers found in the home and more $[6,7,51]$. It may also be found as an environmental pollutant, which may contaminate drinking water as well as any seafood harvested from contaminated ocean waters $[3,14,16]$. The health effects are wide ranging and especially seem to impact the development of children and young adults, the reproductive system, and the immune system, which may lead to carcinomas [45]. In children and young adults, BPA has been correlated with altered energy metabolism leading to obesity, as well as psychological disorders including ADHD and increased aggression under normal circumstances $[26,27,55]$.

Originally, BPA was considered to be safe, since it only acts as a typical chemical toxin at relatively high levels. However, it has only been realised within the last 10 years that BPA is a xenohormone that imitates oestrogen within the body. This means that BPA has been classified as an endocrine disrupting compound (EDC) and interferes with the normal functioning of many signalling processes. Therefore, even nanogram quantities of bisphenol may disrupt normal endocrine signalling [46]. By using standard immunochemical techniques, five different neurochemical markers were investigated. Intrahepatic nerve fibres were stained using antibodies against the neuropeptides: SP, GAL, PACAP, CGRP, and CART. Cocaine and amphetamine regulated transcript (CART), galanin (GAL) and calcitonin gene regulated peptide (CGRP) have been found to be part of the system regulating metabolism and energy utilisation; while substance $\mathrm{P}(\mathrm{SP})$ and pituitary adenylate cyclase activating polypeptide (PACAP) have been found to be correlated with psychological disorders at altered levels.

The particular study presented here is focused upon the effects of BPA on the development of hepatic nerve fibres. By using selected neural markers, this study evaluated the effects of BPA on the nerve fibres of porcine liver in order to determine if the level of expression had changed. These markers are known as "gut-brain" peptides [60]. These peptides are released from the gastrointestinal tract and influence the hypothalamus, mainly, in order to properly regulate physiological responses [47]. This investigation focused upon the liver, since the small intestine is responsible for absorbing most ingested molecules and sending them directly to the liver through the hepatic portal vein [24,32]. Therefore, any vertebrate consuming dietary BPA would expose their liver to that BPA very quickly. This study exposed immature swine to bisphenol for 28 days, and tested hepatic nerve fibres for changes in the characteristics of selected neuronal markers. Swine are often used as an animal model to approximate human physiology [4]. There was a deliberate choice to use the domestic pig for this experiment. There are many similarities in the organisation of the nervous system between humans and pigs, both physiologically and neurochemically $[10,20,34,56]$. Therefore, this species should be a reasonable animal model for studying the influence of pathological substances on the human peripheral nervous system, since the porcine animal model is one of the best approximations of human physiology available. Changes in the nerve fibres after BPA exposure in the developing pig could indicate that BPA is altering these neuropeptides and having unwanted side effects in developing children, which would need to be confirmed by further research.

\section{MATERIALS AND METHODS}

The present study was made on 15 immature sows of the Piétrain $x$ Duroc breed at the age of 8 weeks with an body weight of $18-20 \mathrm{~kg}$. Pigs were kept under typical laboratory conditions adapted for this animal species. The experiment was performed in compliance with the instructions of the Local Ethical Committee for Experiments on Animals in Olsztyn (Poland) decision number (28/2013).

After a 3 day adaptive period, the pigs were randomly divided into three experimental groups: 1) control group - placebo (empty gelatin capsules for 28 days during feeding); 2) experimental group I (received BPA capsules at a dose acceptable under European legislation $-0.05 \mathrm{mg}(50 \mu \mathrm{g}) / \mathrm{kg}$ bw/day); 3) experimental group II (received BPA capsules at a dose 10 times higher than the acceptable level $-0.5 \mathrm{mg} /$ $/ \mathrm{kg}$ bw/day). Every 4 days before the morning feeding, all animals were weighed in order to determine their body weight and calculate the proper dosage of BPA.

After 28 days of BPA administration, the animals were premedicated with Stressnil (Janssen, Belgium, $75 \mu \mathrm{L} / \mathrm{kg}$ of body weight, i.m.). After about $30 \mathrm{~min}$ the animals were euthanised using an overdose of sodium thiopental (Thiopental, Sandoz, Kundl-Rakúsko, Austria, i.v.). Tissues were collected from all sows. 
Table 1. List of primary and secondary antibodies used in this study

\begin{tabular}{|c|c|c|c|c|}
\hline Antisera & Code & Host species & Dilution & Supplier \\
\hline \multicolumn{5}{|c|}{ Primary antibodies } \\
\hline CART & H-003-61 & Rabbit & 1:22000 & $\begin{array}{c}\text { Phoenix Europe } \\
\text { www.phoenixpeptide.com }\end{array}$ \\
\hline SP & $8450-0505$ & Rabbit & 1:10,000 & $\begin{array}{c}\text { Biogenesis Inc. } \\
\text { www.biogenesis.co.uk }\end{array}$ \\
\hline CGRP & 11189 & Rabbit & 1:10,000 & $\begin{array}{l}\text { MP Biomedicals } \\
\text { www.mpbio.com }\end{array}$ \\
\hline GAL & RIN7153 & Rabbit & 1:10,000 & $\begin{array}{c}\text { Peninsula Labs, US; see Bachem AG } \\
\text { www.bachem.com }\end{array}$ \\
\hline PACAP & IHC 8922 & Rabbit & 1:20,000 & $\begin{array}{c}\text { Bachem AG } \\
\text { www.bachem.com }\end{array}$ \\
\hline Reagent & & & Dilution & Supplier \\
\hline \multicolumn{5}{|c|}{ Secondary antibodies } \\
\hline \multicolumn{3}{|c|}{ Biotinylated goat anti-rabbit immunoglobulins } & $1: 1000$ & $\begin{array}{l}\text { E0432, DAKO Corporation, US } \\
\text { www.dakousa.com }\end{array}$ \\
\hline \multicolumn{3}{|c|}{ Biotin conjugated $F(a b)^{\prime}$ fragment of affinity Purified anti-rabbit lgG $(H+L)$} & 1:1000 & $\begin{array}{c}\text { 711-1622, BioTrend, Germany } \\
\text { www.biotrend.com }\end{array}$ \\
\hline \multicolumn{3}{|c|}{ CY3-conjugated Streptavidin } & $1: 9000$ & $\begin{array}{l}\text { 016-160-084, Jackson IR Lab, US } \\
\text { www.jacksonimmuno.com }\end{array}$ \\
\hline
\end{tabular}

CART — cocaine and amphetamine regulated transcript; CGRP — calcitonin gene regulated peptide; GAL — galanin; SP — substance P; PACAP — pituitary adenylate cyclase activating polypeptide

Sections of liver were fixed in $4 \%$ buffered paraformaldehyde, rinsed in phosphate buffer for 3 days and kept in $18 \%$ sucrose at $4^{\circ} \mathrm{C}$. After at least 2 weeks, the fragments of liver were frozen at $-23^{\circ} \mathrm{C}$ and cut into $10 \mu$ m-thick sections using a microtome (Microm, HM 525 , Walldorf, Germany). The sections were subjected to a routine single-labelling immunofluorescence technique according to the method described previously by Gonkowski and Wojtkiewicz [17, 18, 35, 59]. A condensed description of the method is as follows: 45 min of drying; incubation with a blocking solution, which included $10 \%$ normal goat serum, $0.1 \%$ bovine serum albumin, $0.01 \%$ NaN3, Triton $\times-100$ and thimerozal in phosphate buffered saline (PBS) for $1 \mathrm{~h}$; overnight incubation with a polyclonal "primary" antibody directed towards SP, GAL, PACAP, CGRP, or CART; incubation (for $1 \mathrm{~h}$ ) with species-specific antisera conjugated to fluorescein isothiocyanate (FITC) or biotin, which was visualised by a streptavidin-CY3 complex (the specification of primary and secondary antibodies used in the present study is shown in Table 1). Rinsing with PBS $(3 \times 10 \mathrm{~min}, \mathrm{pH}$ 7.4) was performed between each of the stages.

During the present investigation, the standard controls of the specificity of "primary" antibodies were performed. These included pre-absorption of the particular antisera with appropriate antigens, as well as "omission" and "replacement" tests that completely eliminated immunofluorescence signals.

To evaluate the number of SP-, GAL-, PACAP-, CGRP-, and CART-IR intrahepatic nerves, the nerves were counted using a microscopic observation field $\left(0.1 \mathrm{~mm}^{2}\right)$. Nerves immunoreactive to SP, GAL, PACAP, CGRP, and CART were counted in four sections of the liver per animal (in five randomly selected observation fields per section) and the obtained data was pooled and presented as a mean \pm standard error of the mean (SEM). The nerve fibres were visualised under an Olympus BX51 microscope equipped with epi-fluorescence and appropriate filter sets. The obtained results were pooled and presented as a mean \pm SEM. To prevent double counting of the same nerves, the sections of liver evaluated during the present study were located at least $100 \mu \mathrm{m}$ apart. Statistical analysis was carried out via Student's t test (Graphpad Prism v. 6.0; GraphPad Software Inc., San Diego, CA, USA). The differences were considered statistically significant at $\mathrm{p} \leq 0.05$.

\section{RESULTS}

All neuronal markers showed increased expression at the currently recognised legally "safe" level set by the European Union. The majority of these markers were statistically significant. At a concentration of 
Table 2. The change in the expression of neuropeptides in intrahepatic nerves after bisphenol A (BPA) exposure while under physiological conditions

\begin{tabular}{lccc}
\hline \multirow{2}{*}{$\begin{array}{l}\text { Neurochemical } \\
\text { characteristic }\end{array}$} & \multicolumn{3}{c}{ Groups of animals } \\
\cline { 2 - 4 } & CTRL & E1 & E2 \\
\hline CART+ & $1.2 \pm 0.58$ & $4.2 \pm 1.06$ & $8.6 \pm 2.0$ \\
SP+ & $1.4 \pm 0.51$ & $2.2 \pm 0.86$ & $3.6 \pm 1.61$ \\
CGRP+ & $2.0 \pm 0.44$ & $3.0 \pm 1.05$ & $5.8 \pm 1.24$ \\
GAL+ & $0.6 \pm 0.41$ & $3.8 \pm 1.39$ & $5.6 \pm 1.81$ \\
PACAP+ & $2.0 \pm 0.71$ & $7.8 \pm 0.86$ & $9.2 \pm 2.56$ \\
\hline
\end{tabular}

CART — cocaine and amphetamine regulated transcript; CGRP — calcitonin gene regulated peptide; CTRL — control animals; E1 — experimental group I (low-dose BPA group, $0.05 \mathrm{mg} / \mathrm{kg} \mathrm{bw} /$ day for 28 days); E2 - experimental group II (high-dose BPA group, $0.5 \mathrm{mg} / \mathrm{kg}$ bw/day for 28 days); GAL — galanin; SP — substance P; PACAP — pituitary adenylate cyclase activating polypeptide

ten times higher than what is considered to be legally "safe", all neuronal markers showed a marked increase and all were statistically significant. The method used to determine these statistics consisted of determining the number of nerve fibres found in the field of view during the microscopic examination of the three animal groups, as described above. The results are tabulated in Table 2 .

The increase of SP+ nerve fibres was not statistically significant at legally-established safe levels. However, there was an increase at this level of exposure as compared to the control. At an exposure ten times higher than what is legally recommended, SP+ nerve fibres increased to a statistically significant level. The increase of GAL+ nerve fibres was dramatic and statistically significant in all cases. PACAP+ expression was also very dramatic and statistically significant in all cases. The increase of CGRP+ nerve fibres was not statistically significant at legally-established safe levels. However, CGRP+ nerve fibres did increase with statistical significance when BPA exposure was increased to 10 times the recommended limit. The increase of CART + nerve fibres in innervated hepatic sections increased dramatically at exposure levels deemed legally safe under current European Union legislation (including legally safe for children). At an exposure ten times higher than what is recommended, CART+ expression further increased. Both of the CART+ results were statistically significant. Representative images of the immunofluorescence studies are shown in Figure 1.

\section{DISCUSSION}

Knowledge of the innervated liver, in terms of its anatomy and physiology, is quite recent. The first in-depth articles describing hepatic intrinsic nerves have only been published in the last 35 years $[25,31$, 32]. There have been quite a few studies that have investigated neuronal "gut-brain" markers; however as far as we can tell from the literature, this is the first study investigating changes in hepatic immunoreactive nerve fibres after BPA exposure.

It has been observed that the main reaction of the nervous system in response to toxic substances is to change the level of neuronally active substances [36]. Therefore, this study chose to examine five neuronal markers and test their immunoreactivity against control values. Out of several dozen neuronal markers which have been found in neuronal cells and nerve fibres [25, 58], the five factors chosen for this research were found to play key roles in the nervous system as "gut-brain" peptides, since they have been observed quite often in the nerve fibres of the digestive system. Markers such as CGRP, SP, GAL, PACAP and CART have been investigated in earlier studies of nerve-fibres. SP and CGRP have been found to be active in cerebrovascular regulation [23, 37], and are known to be spinal afferent markers [19, 37]. However, SP has been used far more extensively. SP has been shown to be associated with inflammatory diseases, nociception and depression $[42,50]$. GAL has been associated with enhancing the effects of norepinephrine and is a neuromodulator that affects the production of hepatic glucose [53]. Furthermore, GAL has been linked with juvenile onset diabetes mellitus $[13,49]$. There have been correlations made between PACAP and the proper metabolism of glucose, appetite control and food intake $[39,40]$. Recent studies have shown a statistically significant correlation between PACAP and behavioural/psychological disorders, including: stress-related illnesses, memory impairment, hyperactivity, and even PTSD [21, 22, 48]. A neural marker that shows great similarity to PACAP is CART. Several articles have shown a correlation between CART and appetite control, food intake, and the regulation of lipids in adipose tissue $[1,5,38]$. A recent publication has shown a linkage between diabetes mellitus and altered values of CART [11].

Three neurochemical peptides showed significant upregulation. They were CART, GAL and PACAP. The number of CART + nerve fibres were extremely altered and showed drastic upregulation after legally recommended safe dosages. Given the serious pathological trends documented in the literature, these drastic increases of CART + nerve fibres at recommended safe exposure levels should be of great concern. GAL+ 

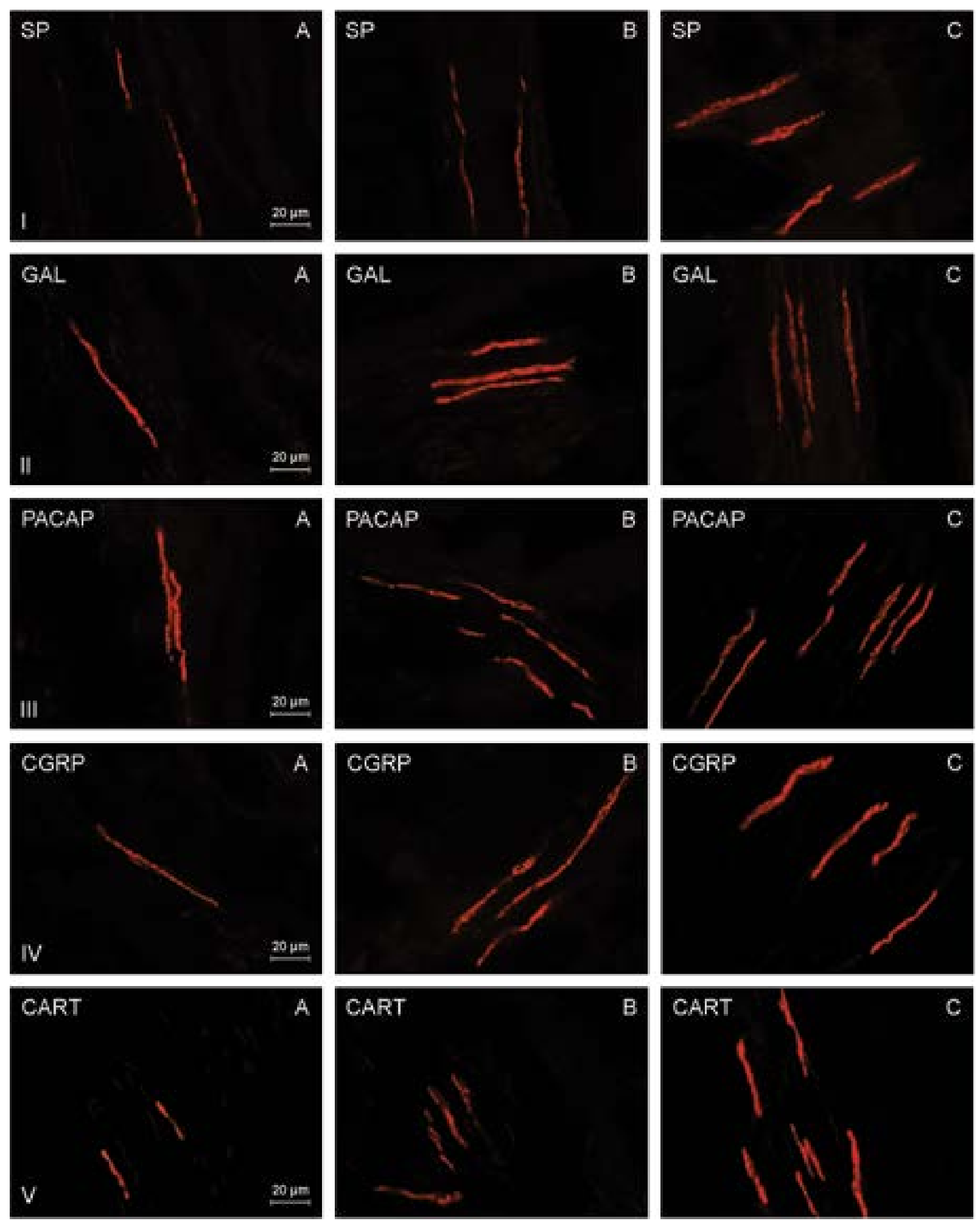

Figure 1. Representative images of immunofluorescent detection of SP-, GAL-, PACAP-, CGRP- and CART-immunoreactive nerve fibres in the liver of control pigs (A) or pigs exposed to low (B) or high dose (C) of bisphenol A; abbreviations - see Table 2.

nerve fibres were also significantly upregulated at recommended safe levels, and show a rather dramatic increase. Incorrect levels of GAL have been indicated in problems with energy metabolism in children, including diabetes mellitus, as previously mentioned $[13,49,53]$. PACAP showed dramatic upregulation at recommended safe exposure levels as well. PACAP has been shown to increase activity within the pituitary 
gland. Therefore, altered levels of PACAP in the central nervous system (CNS) tend to show pathophysiologies associated with psychiatric disorders [48]. Further research should be performed to investigate what these dramatically upregulated neural chemicals may be doing to the peripheral nervous system (PNS).

It has been documented that CART may control metabolism via the CNS, mainly through the proper functioning of appetite regulation $[1,5,11,17,38$, $43,58]$. Thus, altered CART + nerve fibres could be contributing to increased weight gain in children and young adults. Furthermore, this could help to explain the correlation between CART and diabetes mellitus [11] due to the fact that the homeostasis of glucose levels is controlled by the liver. However, further research would need to be performed to verify such a claim. CGRP has been linked with metabolic regulation and is a powerful vasodilator [19, 37]. Increased CGRP+ nerve fibres could be contributing to childhood diabetes and obesity by way of the same mechanisms discussed above for CART+ nerve fibres $[1,5,11,17,38,43,57,58]$. However, further research would need to be performed in order to verify that hypothesis as well as better understand the mechanisms. GAL+ nerve fibres were drastically upregulated as well, and have been shown to cause altered metabolism in similar ways to CART and CGRP $[13,50,53]$. GAL also has a role in sleep regulation and cognition $[15,35]$. The dramatic increases in $\mathrm{GAL}+$ nerve fibres point toward problems with energy metabolism and cognition problems. Since these three neural peptides showed significantly marked upregulation in hepatic nerve fibres, it is not unreasonable to hypothesize a connection between the correlative studies and what has been observed here.

Bisphenol A exposure and childhood obesity have been significantly correlated [54], and a cross-sectional study of school children in China has also correlated BPA exposure with increased body mass index [57]. The studies have shown a statistically significant correlation between the concentration of urinary BPA and an increase of body mass index; not to mention obesity, in adolescents and children. It could be possible that CART, CGRP and GAL upregulation may be contributing to these correlative studies of BPA and childhood metabolic disorders. Further studies with regards to the mechanisms of how this may occur need to be performed. Some studies have already begun $[28,44$, 61]. Other studies have shown an altered regulation of metabolic gene expression to be the mechanism behind how these markers are correlated with diabetes and obesity in children $[12,33,41,52]$. Detailed mechanisms are currently not available, but there are too many correlation studies to be ignored. Since the liver is a vital organ important for the homeostasis of energy levels; one can only speculate, but with some confidence, that there is a connection between correlative studies of bisphenol exposure and altered metabolism; and the very large increases of CART+, CGRP+ and GAL+ hepatic nerve fibres observed in this study.

Substance $P$ was also investigated in this study. SP is known to amplify most cellular processes. Altered SP concentrations have been associated with increased excitation in vivo $[15,29,30]$. Although the increased number of SP+ nerve fibres was not statistically significant at legally recommended safe levels, it did show an increase. Furthermore, at a 10-fold higher than recommended concentration of BPA, the upregulation was statistically significant. Therefore, bisphenol exposure may be increasing the expression of SP which may further enhance the effects of the other gut-brain neuropeptides. However, at this time no mechanisms are available, and a causative relation is only conjecture. This is the major limitation of this study. Bisphenol research is so new that there are very few mechanistic studies available. Unfortunately, the mechanisms are extremely complex, but it is hoped that this type of research may be a starting point for more research.

\section{CONCLUSIONS}

This particular xenoestrogen (BPA) is literally found everywhere today and perhaps even a majority of parents still do not know about the dangers of bisphenol exposure [2-9]. Therefore, it is our recommendation to lower the suggested safe levels of bisphenol exposure, and to further increase the awareness of the public about the potential dangers of bisphenol especially in relation to children and young adults.

\section{Acknowledgements}

This study was supported by the Faculty of Medical Sciences, University of Warmia and Mazury in Olsztyn, Poland and KNOW (Leading National Research Centre) Scientific Consortium "Healthy Animal — Safe Food", decision of Ministry of Science and Higher Education No.05-1/KNOW2/2015.

\section{REFERENCES}

1. Akash G, Kaniganti T, Tiwari NK, et al. Differential distribution and energy status-dependent regulation of the four CART neuropeptide genes in the zebrafish brain. 
J Comp Neurol. 2014; 522(10): 2266-2285, doi: 10.1002/ cne.23532, indexed in Pubmed: 24374761.

2. Barberi M, Muciaccia B, Morelli M, et al. Expression localisation and functional activity of pituitary adenylate cyclase-activating polypeptide, vasoactive intestinal polypeptide and their receptors in mouse ovary. Reproduction. 2007; 134(2): 281-292, doi: 10.1530/rep-07-0051.

3. Barsiene J, Syvokiene J, Bjornstad A. Induction of micronuclei and other nuclear abnormalities in mussels exposed to bisphenol A, diallyl phthalate and tetrabromodiphenyl ether-47. Aquat Toxicol. 2006; 78 Suppl 1: S105-S108, doi: 10.1016/j.aquatox.2006.02.023, indexed in Pubmed: 16616789.

4. Bassols A, Costa C, Eckersall PD, et al. The pig as an animal model for human pathologies: A proteomics perspective. Proteomics Clin Appl. 2014; 8(9-10): 715-731, doi: 10.1002/ prca.201300099, indexed in Pubmed: 25092613.

5. Bharne AP, Borkar CD, Subhedar NK, et al. Differential expression of CART in feeding and reward circuits in binge eating rat model. Behav Brain Res. 2015; 291 : 219-231, doi: 10.1016/j.bbr.2015.05.030, indexed in Pubmed: 26008155.

6. Becerra V, Odermatt J. Detection and quantification of traces of bisphenol $A$ and bisphenol $S$ in paper samples using analytical pyrolysis-GC/MS. Analyst. 2012; 137(9): 2250-2259, doi: 10.1039/c2an15961a, indexed in Pubmed: 22428152.

7. Beronius $A$, Rudén $C$, Håkansson $H$, et al. Risk to all or none? Reproduct Toxicol. 2010; 29(2): 132-146, doi: 10.1016/j.reprotox.2009.11.007, indexed in Pubmed: 19931376.

8. Braun JM, Yolton K, Dietrich KN, et al. Prenatal bisphenol A exposure and early childhood behavior. Environ Health Perspect. 2009; 117(12): 1945-1952, doi: 10.1289/ ehp.0900979, indexed in Pubmed: 20049216.

9. Braun JM, Kalkbrenner $A E$, Calafat $A M$, et al. Impact of early-life bisphenol A exposure on behavior and executive function in children. Pediatrics. $2011 ; 128(5)$ : 873-882, doi: 10.1542/peds.2011-1335, indexed in Pubmed: 22025598.

10. Brown DR, Timmermans JP. Lessons from the porcine enteric nervous system. Neurogastroenterol Motil. 2004; 16 Suppl 1: 50-54, doi: 10.1111/j.1743-3150.2004.00475.x, indexed in Pubmed: 15066005.

11. Bulc M, Gonkowski S, Całka J. Expression of Cocaine and Amphetamine Regulated Transcript (CART) in the Porcine Intramural Neurons of Stomach in the Course of Experimentally Induced Diabetes Mellitus. J Mol Neurosci. 2015; 57(3): 376-385, doi: 10.1007/s12031-015-0618-2, indexed in Pubmed: 26266486.

12. Carolan E, Hogan AE, Corrigan M, et al. The impact of childhood obesity on inflammation, innate immune cell frequency, and metabolic microRNA expression. J Clin Endocrinol Metab. 2014; 99(3): E474-E478, doi: 10.1210/ jc. 2013-3529, indexed in Pubmed: 24423308.

13. Celi F, Bini V, Papi F, et al. Circulating acylated and total ghrelin and galanin in children with insulin-treated type 1 diabetes: relationship to insulin therapy, metabolic control and pubertal development. Clin Endocrinol (Oxf). 2005; 63(2): 139-145, doi: 10.1111/j.1365-2265.2005.02313.x, indexed in Pubmed: 16060906.
14. Dabrowska H, Kopko O, Lehtonen KK, et al. An integrated assessment of pollution and biological effects in flounder, mussels and sediment in the southern Baltic Sea coastal area. Environ Sci Pollut Res Int. 2017; 24(4): 3626-3639, doi: 10.1007/ s11356-016-8117-8, indexed in Pubmed: 27885579.

15. DeLeón M, Coveñas R, Chadi G, et al. Subpopulations of primary sensory neurons show coexistence of neuropeptides and glucocorticoid receptors in the rat spinal and trigeminal ganglia. Brain Res. 1994; 636(2): 338-342, indexed in Pubmed: 8012818.

16. Duong CN, Ra JS, Cho J, et al. Estrogenic chemicals and estrogenicity in river waters of South Korea and seven Asian countries. Chemosphere. 2010; 78(3): 286-293, doi: 10.1016/j.chemosphere.2009.10.048, indexed in Pubmed: 19931116.

17. Gonkowski S, Kamińska B, Landowski P, et al. Immunohistochemical distribution of cocaine- and amphetamine-regulated transcript peptide - like immunoreactive (CART-LI) nerve fibers and various degree of co-localization with other neuronal factors in the circular muscle layer of human descending colon. Histol Histopathol. 2013; 28(7): 851-858, doi: 10.14670/HH-28.851, indexed in Pubmed: 23277430.

18. Gonkowski S, Rowniak M, Wojtkiewicz J. Zinc Transporter 3 (ZnT3) in the Enteric Nervous System of the Porcine lleum in Physiological Conditions and during Experimental Inflammation. Int J Mol Sci. 2017; 18(2), doi: 10.3390/ ijms18020338, indexed in Pubmed: 28178198.

19. Gonkowski S, Burlinski P, Calka J. Proliferative enteropathy (PE): Induced changes in galanin-like immunoreactivity in the enteric nervous system of the porcine distal colon. Acta Veterinaria. 2009; 59(4): 321-330, doi: 10.2298/avb0904321g.

20. Guo J, Zhao MH, Shin KT, et al. The possible molecular mechanisms of bisphenol A action on porcine early embryonic development. Sci Rep. 2017; 7(1): 8632, doi: 10.1038/ s41598-017-09282-2, indexed in Pubmed: 28819136.

21. Hammack SE, May V. Pituitary adenylate cyclase activating polypeptide in stress-related disorders: data convergence from animal and human studies. Biol Psychiatry. 2015; 78(3): 167-177, doi: 10.1016/j.biopsych.2014.12.003, indexed in Pubmed: 25636177.

22. Hashimoto H. [Psychiatric implications of PACAP signaling pathway]. Nihon Shinkei Seishin Yakurigaku Zasshi. 2012; 32(3): 133-137, indexed in Pubmed: 22834101.

23. Hökfelt T, Kellerth JO, Nilsson G, et al. Experimental immunohistochemical studies on the localization and distribution of substance $P$ in cat primary sensory neurons. Brain Res. 1975; 100(2): 235-252, indexed in Pubmed: 1104079.

24. Itoh K, Yaoi T, Fushiki S. Bisphenol A, an endocrine-disrupting chemical, and brain development. Neuropathology. 2012; 32(4): 447-457, doi: 10.1111/j.14401789.2011.01287.x, indexed in Pubmed: 22239237.

25. Jensen KJ, Alpini G, Glaser S. Hepatic nervous system and neurobiology of the liver. Compr Physiol. 2013; 3(2): 655-665, doi: 10.1002/cphy.c120018, indexed in Pubmed: 23720325.

26. Kinch $C D$, Ibhazehiebo $K$, Jeong JH, et al. Low-dose exposure to bisphenol $\mathrm{A}$ and replacement bisphenol $\mathrm{S}$ induces precocious hypothalamic neurogenesis in embryonic zebrafish. Proc Natl Acad Sci U S A. 2015; 112(5): 1475-1480, doi: 10.1073/pnas.1417731112, indexed in Pubmed: 25583509. 
27. Kitraki E, Nalvarte I, Alavian-Ghavanini A, et al. Effects of pre- and post-natal exposure to bisphenol $A$ on the stress system. Endocrine Disruptors. 2016; 4(1): e1184775, doi: 10.1080/23273747.2016.1184775.

28. Kolšek K, Mavri J, Sollner Dolenc M. Reactivity of bisphenol A-3,4-quinone with DNA. A quantum chemical study. Toxicol In Vitro. 2012; 26(1): 102-106, doi: 10.1016/j. tiv.2011.11.003, indexed in Pubmed: 22120823.

29. Kozłowska A, Wojtkiewicz J, Majewski M, et al. Localization of substance $P$, calcitonin gene related peptide and galanin in the nerve fibers of porcine cystic ovaries. Folia Histochem Cytobiol. 2011; 49(4): 622-630, indexed in Pubmed: 22252756.

30. Lasaga M, Debeljuk L. Tachykinins and the hypothalamo-pituitary-gonadal axis: An update. Peptides. 2011; 32(9): 1972-1978, doi: 10.1016/j.peptides.2011.07.009, indexed in Pubmed: 21801774.

31. Lautt WW. Hepatic nerves: a review of their functions and effects. Can J Physiol Pharmacol. 1980; 58(2): 105-123, indexed in Pubmed: 6991079.

32. Lautt WW. Hepatic circulation: Physiology and pathophysiology. In Colloquium Series on Integrated Systems: Physiology: from Molecule to Function. Morgan \& Claypool Life Sciences: San Rafael, CA, USA. 2009; book 1: 83-119.

33. Lian J, De Santis M, He M, et al. Risperidone-induced weight gain and reduced locomotor activity in juvenile female rats: The role of histaminergic and NPY pathways. Pharmacol Res. 2015; 95-96: 20-26, doi: 10.1016/j. phrs.2015.03.004, indexed in Pubmed: 25782398.

34. Litten-Brown JC, Corson AM, Clarke L. Porcine models for the metabolic syndrome, digestive and bone disorders: a general overview. Animal. 2010; 4(6): 899-920, doi: 10.1017/ S1751731110000200, indexed in Pubmed: 22444262.

35. Majewski M, Bossowska A, Gonkowski S, et al. Neither axotomy nor target-tissue inflammation changes the NOSor VIP-synthesis rate in distal bowel-projecting neurons of the porcine inferior mesenteric ganglion (IMG). Folia Histochem Cytobiol. 2002; 40(2): 151-152, indexed in Pubmed: 12056620.

36. Makowska K, Obremski K, Zielonka L, et al. The influence of low doses of zearalenone and T-2 toxin on calcitonin gene related peptide-like immunoreactive (CGRP-LI) neurons in the ENS of the porcine descending colon. Toxins (Basel). 2017; 9(3), doi: 10.3390/toxins9030098, indexed in Pubmed: 28287437.

37. McCulloch J, Uddman R, Kingman TA, et al. Calcitonin gene-related peptide: functional role in cerebrovascular regulation. Proc Natl Acad Sci U S A. 1986; 83(15): 5731-5735, doi: 10.1073/pnas.83.15.5731, indexed in Pubmed: 3488550.

38. Meisner H, Carter JR. Regulation of lipolysis in adipose tissue. Horiz Biochem Biophys. 1977; 4: 91-129, indexed in Pubmed: 202557.

39. Mizuno Y, Kondo K, Terashima Y, et al. Anorectic effect of pituitary adenylate cyclase activating polypeptide (PACAP) in rats: lack of evidence for involvement of hypothalamic neuropeptide gene expression. J Neuroendocrinol. 1998; 10(8): 611-616, indexed in Pubmed: 9725713.

40. Morley JE, Horowitz M, Morley PM, et al. Pituitary adenylate cyclase activating polypeptide (PACAP) reduces food intake in mice. Peptides. 1992; 13(6): 1133-1135, indexed in Pubmed: 1494495.
41. Mueller K, Sacher J, Arelin K, et al. Overweight and obesity are associated with neuronal injury in the human cerebellum and hippocampus in young adults: a combined MRI, serum marker and gene expression study. Transl Psychiatry. 2012; 2: e200, doi: 10.1038/tp.2012.121, indexed in Pubmed: 23212584.

42. O'Connor TM, O'Connell J, O'Brien DI, et al. The role of substance $P$ in inflammatory disease. J Cell Physiol. 2004; 201(2): 167-180, doi: 10.1002/jcp.20061, indexed in Pubmed: 15334652.

43. Palus K, Rytel L. Co-localisation of cocaine- and amphetamine-regulated transcript peptide and vasoactive intestinal polypeptide in the myenteric plexus of the porcine transverse colon. Folia Morphol. 2013; 72(4): 328-332, indexed in Pubmed: 24402755.

44. Michaela P, Mária K, Silvia H, et al. Bisphenol A differently inhibits CaV3.1, CaV3.2 and CaV3.3 calcium channels. Arch Exp Pathol Pharmakol. 2013; 387(2): 153-163, doi: 10.1007/s00210-013-0932-6.

45. Rachoń D. Endocrine disrupting chemicals (EDCs) and female cancer: Informing the patients. Rev Endocr Metab Disord. 2015; 16(4): 359-364, doi: 10.1007/s11154-0169332-9, indexed in Pubmed: 26831296.

46. Reif DM, Martin MT, Tan SW, et al. Endocrine profiling and prioritization of environmental chemicals using ToxCast data. Environ Health Perspect. 2010; 118(12): 1714-1720, doi: 10.1289/ehp.1002180, indexed in Pubmed: 20826373.

47. Rękawek W, Sobiech P, Gonkowski S, et al. Distribution and chemical coding patterns of cocaine- and amphetamine-regulated transcript-like immunoreactive (CART-LI) neurons in the enteric nervous system of the porcine stomach cardia. Pol J Vet Sci. 2015; 18(3): 515-522, doi: 10.1515/ pjvs-2015-0067, indexed in Pubmed: 26618583.

48. Jovanovic T, Norrholm SD, Davis J, et al. Post-traumatic stress disorder is associated with PACAP and the PAC1 receptor. Nature. 2011; 470(7335): 492-497, doi: 10.1038/ nature09856, indexed in Pubmed: 21350482.

49. Sandoval-Alzate HF, Agudelo-Zapata Y, González-Clavijo $A M$, et al. Serum galanin levels in young healthy lean and obese non-diabetic men during an oral glucose tolerance test. Sci Rep. 2016; 6: 31661, doi: 10.1038/srep31661, indexed in Pubmed: 27550417.

50. Schwarz MJ, Ackenheil M. The role of substance $P$ in depression: therapeutic implications. Dialogues Clin Neurosci. 2002; 4(1): 21-29, indexed in Pubmed: 22033776.

51. Simoneau C, Valzacchi S, Morkunas V, et al. Comparison of migration from polyethersulphone and polycarbonate baby bottles. Food Addit Contam Part A Chem Anal Control Expo Risk Assess. 2011; 28(12): 1763-1768, doi: 10.1080 /19440049.2011.604644, indexed in Pubmed: 21988286.

52. Surendran S, Kondapaka SB. Altered expression of neuronal nitric oxide synthase in the duodenum longitudinal muscle-myenteric plexus of obesity induced diabetes mouse: implications on enteric neurodegeneration. Biochem Biophys Res Commun. 2005; 338(2): 919-922, doi: 10.1016/j. bbrc.2005.10.039, indexed in Pubmed: 16256069.

53. Taborsky GJ, Dunning BE, Havel PJ, et al. The canine sympathetic neuropeptide galanin: a neurotransmitter in pancreas, a neuromodulator in liver. Horm Metab Res. 1999; 31(5): 351-354, doi: 10.1055/s-2007-978752, indexed in Pubmed: 10422734. 
54. Trasande L, Attina TM, Blustein J. Association between urinary bisphenol A concentration and obesity prevalence in children and adolescents. JAMA. 2012; 308(11): 1113-1121, doi: 10.1001/2012.jama.11461, indexed in Pubmed: 22990270.

55. Vandenberg L, Ehrlich S, Belcher S, et al. Low dose effects of bisphenol A. Endocrine Disruptors. 2014; 1(1): e26490, doi: 10.4161/endo. 26490 .

56. Verma N, Rettenmeier AW, Schmitz-Spanke S. Recent advances in the use of Sus scrofa (pig) as a model system for proteomic studies. Proteomics. 2011; 11(4): 776-793, doi: 10.1002/pmic.201000320, indexed in Pubmed: 21229584.

57. Wang Hx, Zhou $Y$, Tang $C x$, et al. Association between bisphenol $A$ exposure and body mass index in Chinese school children: a cross-sectional study. Environ Health. 2012; 11: 79, doi: 10.1186/1476-069X-11-79, indexed in Pubmed: 23083070.

58. Wojtkiewicz J, Gonkowski S, Bladowski M, et al. Characterisation of cocaine- and amphetamine-regulated transcript-like immunoreactive (CART-LI) enteric neurons in the porcine small intestine. Acta Vet Hung. 2012; 60(3): 371-381, doi: 10.1556/AVet.2012.032, indexed in Pubmed: 22903082.

59. Wojtkiewicz J, Makowska K, Bejer-Olenska E, et al. Zinc transporter 3 (Znt3) as an active substance in the enteric nervous system of the porcine esophagus. J Mol Neurosci. 2017; 61 (3): 315-324, doi: 10.1007/s12031-016-0854-0, indexed in Pubmed: 27796869.

60. Wojtkiewicz J, Rytel L, Makowska K, et al. Co-localization of zinc transporter 3 (ZnT3) with sensory neuromediators and/or neuromodulators in the enteric nervous system of the porcine esophagus. Biometals. 2017; 30(3): 393-403, doi: 10.1007/s10534-017-0014-1, indexed in Pubmed: 28417221.

61. Zalko D, Soto AM, Canlet C, et al. Bisphenol a exposure disrupts neurotransmitters through modulation of transaminase activity in the brain of rodents. Endocrinology. 2016; 157(5): 1736-1739, doi: 10.1210/en.2016-1207, indexed in Pubmed: 27149041. 